\title{
A STUDY OF INTERLEUKIN-15 (IL 15) GENE POLYMORPHISMS IN PAKISTANI PATIENTS WITH RHEUMATOID ARTHRITIS (RA)
}

\author{
KIANI A.K. ${ }^{1}$, JAHANGIR S. ${ }^{1}$, JOHN P. ${ }^{1 *}$, BHATTI A. ${ }^{1}$, MOEEZ S. ${ }^{1}$, ASHRAF M. ${ }^{1}$, ALI A. ${ }^{1}$, MALIK J.M. ${ }^{2}$ AND \\ IQBAL T. ${ }^{3}$
}

1Department of Health Care Biotechnology, Atta-ur-Rahman School of Applied Biosciences (ASAB), National University of Sciences and Technology (NUST), H-12, Islamabad, Pakistan.

${ }^{2}$ Arthritis Research Center, Rahmat Noor Clinic, 120 Westridge-1, Peshawar Road, Rawalpindi, Pakistan.

${ }^{3}$ Shifa College of Medicine, Shifa International Hospital, Sector H-8, Islamabad, Pakistan.

*Corresponding Author: Email- pjohn@asab.nust.edu.pk

Received: April 13, 2013; Accepted: May 21, 2013

\begin{abstract}
leukin-15 gene might play a role in rheumatoid arthritis. morphisms. Results were analyzed statistically for any significant association of these polymorphisms with rheumatoid arthritis. our patients. matoid Arthritis needs to be investigated.

Keywords- Interleukin 15, Rheumatoid arthritis, Polymorphism, SNP, Pakistan, DNA, Primers, Genotype

Running Title- IL 15 Gene Polymorphism in RA.
\end{abstract}

Background- Aim of the present study was to explore the association of two single nucleotide polymorphisms (SNPs), including rs4956403 (SNP-1) and rs3806798 (SNP-2) located in the 5' UTR region of interleukin 15 gene in rheumatoid arthritis of Pakistani patients. Interleukin-15 is one of the key cytokines in the pathogenesis of rheumatoid arthritis. The genetic polymorphisms located in the regulatory regions of inter-

Methodology- Fresh blood samples were collected from different hospitals. Allele specific PCR was employed for the analysis of these poly-

Results- The results of our study showed that SNP-1 and SNP-2 located in interleukin-15 gene are not associated with rheumatoid arthritis in

Conclusion- Any other Single nucleotide polymorphisms (SNPs) located in the regulatory and untranslated regions of IL15 gene may have association with rheumatoid arthritis, for which large scale data is required. Other molecules implicated in the inflammatory pathway of Rheu-

Citation: Kiani A.K., et al. (2013) A Study of Interleukin-15 (IL 15) Gene Polymorphisms in Pakistani Patients with Rheumatoid Arthritis (RA). International Journal of Genetics, ISSN: 0975-2862 \& E-ISSN: 0975-9158, Volume 5, Issue 2, pp.-139-141.

Copyright: Copyright@2013 Kiani A.K., et al. This is an open-access article distributed under the terms of the Creative Commons Attribution License, which permits unrestricted use, distribution and reproduction in any medium, provided the original author and source are credited.

\section{Introduction}

Rheumatoid arthritis (RA) is a systemic chronic inflammatory disease that targets synovial membranes, bones and joints. Worldwide, its prevalence is about 0.3 -to $1.2 \%$ [1]. It is a multi-factorial disease and a number of factors contribute to the development and pathogenesis of the disease. Contribution of genetic factors towards RA ranges from 50-60\% [2,3]. Human leukocyte Antigen (HLA) locus is the most important genetic risk factor in RA [4,5]. Major environmental factors that contribute to increased risk of RA include smoking, diet and hormones. Smoking, however, is usually considered the most important risk factor. Smoking can lead to 1.3-2.4 times increased risk of RA [6]. Genome Wide Association Studies (GWAS) have emphasized on the association of single nucleotide polymorphisms (SNPs) with RA. SNPs are particularly useful as every individual is uniquely characterized by a set of at least 3 million common SNPs that are distributed across the genome. SNPs, in turn, can determine the response of an individual towards differ- ent environmental factors.

Cytokines are important component of the immune system. These cytokines integrate the immune regulatory pathways that ultimately lead to different autoimmune diseases including RA. T-helper cell ( $T_{H}$ cell) cytokines are the most important of all the cytokines that might play a role in RA [7]. Interleukin-15 (IL 15) is an important T cell cytokine that shares structural similarity to interleukin-2 (IL-2). The receptor for these two cytokines is complex, composed of IL12/IL 15 receptor beta chains (Cluster of differentiation-122, CD122) and a common gamma chain (Cluster of Differentiaiton-132, CD-132). It is primarily secreted by mononuclear phagocytes. It regulates $T$ and natural killer cell activation and proliferation.

The levels of IL 15 have been observed to be increased in RA as compared to other rheumatic diseases [8]. It is secreted by fibroblasts and macrophages in the inflamed synovial membrane during RA [9]. Increased levels of this cytokine may lead to the recruitment 
and activation of synovial T-cells [10]. It leads to the differentiation of the osteoclast progenitors which is the key step that leads towards the bone deterioration [11].

The expression of IL 15 is regulated at both transcriptional and post -transcriptional levels. Genetic polymorphisms in the genes of the cytokines can lead to the variations in the levels of these cytokines in the body [12]. Thus polymorphisms located in the regulatory regions of IL15 gene might play a role in pathogenesis of immune system diseases.

The above mentioned findings and observations encouraged us to perform a case-control association study in Pakistani patients to examine the role of IL 15 gene polymorphisms in the susceptibility to RA. To the best of our knowledge this is the first case control study in context to Pakistani RA patients.

\section{Materials and Methods}

The work designed was a case control study. As a whole, 100 cases and 100 controls were included in the study. The patients included in the case group were clinically diagnosed by rheumatologist and the American Criteria of Rheumatology (ACR-2011) criterion was used. Written informed consent was obtained from the patient to participate in the study. The ratio of females and males included in case group was $80 \%$ and $20 \%$ respectively. The average age of the patients included in the study was $46.38 \pm 10.67$ years. The ratio of females and males in the control group was $77 \%$ and $23 \%$ respectively. The average age of the healthy individuals was 32.68 \pm 5.79 years. Blood samples were collected from the affected and normal individuals. Genomic DNA was extracted from blood samples by phenol-chloroform method and was used for PCR amplification. SNPs selected for the association study are located in 5' UTR region of IL 15 gene at position -831 (rs4956403 / SNP-1) and -475 (rs3806798 / SNP-2). Primers were manually designed for allele specific PCR [Table-1].

Allele specific PCR was carried out to check the presence of polymorphisms in the study population. PCR conditions included a template denaturation at $95^{\circ} \mathrm{C}$ for 5 minutes followed by 35 cycles of PCR amplification. Each PCR cycle further consisted of 3 steps: 1 minute at $95^{\circ} \mathrm{C}$ for the denaturation of template DNA strands into single strands, 45 seconds at $55^{\circ} \mathrm{C}$ to allow the annealing of the primers to their respective target sites on DNA and 1 minute and 20 seconds for extension of the complementary DNA strand from the annealed primers. These 35 cycles were followed by synthesis of any unextended strands by Taq polymerase for 10 minutes at $72^{\circ} \mathrm{C}$. PCR products were then analyzed by $2 \%$ agarose gel. Data was statistically analyzed by using Statistical Practices for Social Sciences (SPSS) and Fischer exact test was applied for association analysis of the polymorphisms in the study population Graphpad PRISM.

Table 1- Primers designed for SNP-1 and SNP-2 located in the regulatory region of interleukin-15 (IL 15) gene. The mutated nucleotide has been indicated in red color

\begin{tabular}{|c|c|c|c|c|c|c|}
\hline SNP & Database identification & Gene Lc & ocation Change & Forward Primers & Reverse Primers & Product size (base pairs) \\
\hline SNP-1 & rs 4956403 & 5' UTR & $\mathrm{C} \rightarrow \mathrm{T}$ & $\begin{array}{l}\text { 5'1GGAAGACATCATTTTCTCTGAACC13' } \\
\text { 5'1GGAAGACATCATTTTCTCTGAACT13' }\end{array}$ & AAACTT1 & 3' 461 \\
\hline SNP-2 2 & rs3806798 & 5' UTR & $\mathrm{T} \rightarrow \mathrm{A}$ & $\begin{array}{l}\text { 5'1AACATTTCCCCTAGTTGGACT13' } \\
\text { 5'1AACATTTCCCCTAGTTGGACA13' }\end{array}$ & 5'1AAAGAGAAAGAGCCGGGAG13' & 470 \\
\hline
\end{tabular}

\section{Result}

The genotype frequencies of the screened polymorphisms were not found to be significantly different from those predicted by HardyWeinberg equilibrium (HWE) in healthy subjects. All the possible combinations of alleles were observed in the study subjects for both of the SNPs [Fig-1]. The observed genotype frequencies have been illustrated in [Table-2]. The frequency of all the possible genotypes did not showed any significant difference in the patients and the healthy individuals [Table-2].

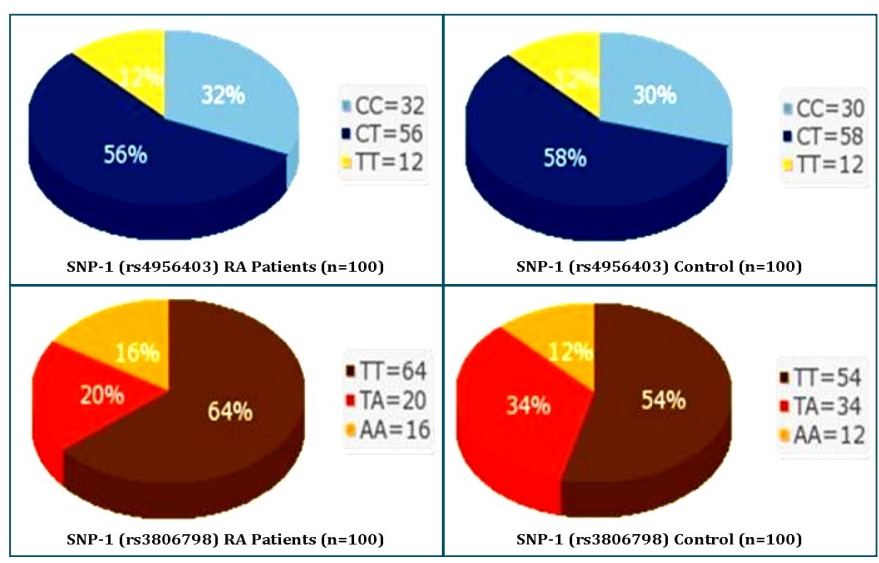

Fig. 1- Distribution of the study subjects across different genotypes for the studied polymorphisms.

Correlation of respective SNP's with clinic-pathological findings and age has been shown in [Table-3]. The association analysis showed that the genotypes of the individual, with respect to respective SNPs, were not linked to any of the disease attribute or gender of the individual [Table-3].

\section{Discussion}

The levels of IL 15 are known to increase significantly in RA patients [8]. The expression of this cytokine is known to be regulated at both pre-transcriptional and post-transcriptional levels. SNPs located in the regulatory regions of this cytokine can therefore play a significant contribution towards pre-disposition towards RA. However, the results of our study did not confirm any considerable association of these two polymorphisms with RA.

The SNPs located in IL15 gene might affect the characteristic clinical features of the disease as these polymorphisms can lead to altered levels of this cytokine. These altered levels can in turn determine the extent of damage caused by the effector cells in the inflamed synovium and rheumatoid joints. These polymorphisms can thus determine the clinical presentation of RA. The association of these polymorphisms was therefore studied in relation to different characteristic features of RA. These characteristic features included age of onset of the disease, duration of symptoms, presence of migratory arthritis, the duration of morning stiffness and the severity of the disease. The association analysis of the observed genotypes and the occurrence and extent of these clinical features indicated that there was no significant association between these clinical features of the disease and IL15 gene polymorphisms being studied. This indicates that the actual genetic determinants of the clinical features of RA are located either at other positions in IL15 gene 
or they might be located in the genes of other candidate genes for RA.

$\mathrm{RA}$ is more common among females. The polymorphisms that affect the regulation of key regulatory molecules involved in the pathogenesis of RA might contribute towards RA in a sex-dependent manner. The association of rs4956403 and rs3806798 was therefore analyzed in RA patients in relation to the sex of the patient, in our study. The results of the statistical analysis showed there was no significant difference between RA affected females and males in relation to the occurrence of these polymorphisms.

The results of our study indicated no significant association of any of the studied IL15 gene polymorphisms in RA patients of Pakistani origin. These results are consistent with a previous association study conducted in Spanish population, where 13 different SNPs were analyzed in association to RA. These 13 SNPs included six SNPs located in 5' UTR region, three SNPs located in the intronic region and four located in 3'UTR region. The resulting data indicated no significant difference in the distribution of the observed genotypes in RA patients and healthy individuals. rs4956403 and rs3806798 located in the 5' UTR region of IL15 gene, were also analyzed in that study and were not found to be significantly associated with RA [13].

Table 2- Genotype and allele frequencies of SNP-1 and SNP-2 in RA patients and controls

\begin{tabular}{|c|c|c|c|c|c|c|c|c|c|c|c|c|}
\hline \multirow{2}{*}{ SNP } & \multirow{2}{*}{$\begin{array}{l}\text { dbSNP } \\
\text { number }\end{array}$} & \multicolumn{2}{|c|}{ Alleles } & \multirow{2}{*}{\multicolumn{2}{|c|}{ Patients ( $n=100$ ) }} & & \multicolumn{2}{|r|}{ Controls $(n=100)$} & \multirow{2}{*}{\multicolumn{2}{|c|}{$\begin{array}{c}\text { MAF }^{*} \\
\text { Patients }\end{array}$}} & \multirow{2}{*}{$\begin{array}{c}\text { MAF* }^{*} \\
\text { Controls }\end{array}$} & \multirow{2}{*}{ p-value } \\
\hline & & & b & & & Homozygous (bb) & Homozygous (aa) & Heterozygous (a/b) & & & & \\
\hline SNP-1 & rs4956403 & C & $\mathrm{T}$ & 32 & 56 & 12 & 30 & 58 & 12 & 40 & 41 & 0.3 \\
\hline SNP-2 & rs3806798 & $\mathrm{T}$ & $A$ & 64 & 20 & 16 & 54 & 34 & 12 & 26 & 29 & 1 \\
\hline
\end{tabular}

*MAF=Minor Allele Frequency

Table 3- The association of SNP-1 and SNP-2 with different clinical features of rheumatoid arthritis (RA) and sex of the patient

\begin{tabular}{|c|c|c|c|c|c|c|c|}
\hline \multirow{2}{*}{ SNP } & \multirow{2}{*}{ db SNP number } & \multicolumn{6}{|c|}{ p-value } \\
\hline & & Age of onset & Duration of symptoms & Duration of morning stiffness & Migratory arthritis & Disease severity & Sex \\
\hline SNP-1 & rs4956403 & 0.1 & 1.7 & 0.7 & 0.4 & 0.8 & 0.4 \\
\hline SNP-2 & rs3806798 & 0.5 & 0.4 & 0.3 & 0.1 & 0.4 & 0.3 \\
\hline
\end{tabular}

\section{Conclusions}

In summary, the results of our study showed that SNP1 and SNP2 in IL 15 gene are not associated with RA in studied Pakistani patients. However, other molecules implicated in the inflammatory pathway of RA, needs to be investigated for association with RA in disease pathogenesis. Other polymorphisms of IL 15 located in the regulatory and untranslated regions may have significant association towards RA, for analysis of which large scale data is required.

\section{Acknowledgements}

This work was supported by Higher Education Commission (HEC) in Pakistan. We are thankful to all the individuals who participated in this study.

\section{Conflict of Interest}

This study has no conflict of interests. All authors have seen the original manuscript and they have approved it.

\section{References}

[1] Carmona L., Villaverde V., Hernández-García C., Ballina J., Gabriel R. and Laffon A. (2002) Rheumatology, 41(1), 88-95.

[2] Seldin M.F., Amos C.I., Ward R. and Gregersen P.K. (1999) Arthritis and Rheumatism, 42, 1071-1079.

[3] MacGregor A.J., Snieder H., Rigby A.S., Koskenvuo M., Kaprio J., Aho K. and Silman A.J. (2000) Arthritis and Rheumatism, 43 (1), 30.

[4] Bowes J. and Barton A. (2008) Rheumatology (Oxford), 47(4), 399-402.

[5] Imboden J.B. (2009) Annals of the Rheumatic Diseases, 4, 417434.

[6] Silman A.J. and Hochberg M.C. (2001) Epidemiology of the rheumatic diseases, 2nd ed., Oxford University Press, New York.

[7] Firestein G.S. (2003) Nature, 423(6937), 356-361.
[8] Thurkow E.W., van der Heijden I.M., Breedveld F.C., Smeets T.J., Daha M.R., Kluin P.M., Meinders A.E. and Tak P.P. (1997) The Journal of Pathology, 181 (4), 444-450.

[9] Mclnnes I.B., Leung B.P, Sturrock R.D., Field M. and Liew F.Y. (1997) Nature Medicine, 3, 189-195.

[10]McInnes I.B., Al-Mughales J., Field M., Leung B.P., Huang F., Dixon R., Sturrock R.D., Wilkinson P.C. and Liew F.Y. (1996) Nature Medicine, 2 (2), 175-182.

[11]Ogata Y., Kukita A., Kukita T., Komine M., Miyahara A., Miyazaki S. and Kohashi O. (1999) Journal of Immunology, 162 (5), 2754-2760.

[12]Ollier W.E. (2004) Cytokine, 28, 174-178.

[13]Rueda B., López-Nevot M.A., González-Gay M.A., Balsa A., Pascual-Salcedo D., Garcia A., Gonzalez A. and Martin J. (2007) Cytokine, 38(2), 84-89. 